\title{
WATER RESOURCES DEPLOYMENT MODEL FOR PINGSHUI RIVER BASIN
}

\author{
HUANG, B. B. ${ }^{1,2, *}-$ NIU, J. T. ${ }^{2}-$ GUI, F. L. ${ }^{1}-$ ZHANG, X. H. ${ }^{2}$ \\ ${ }^{1}$ JiangXi Engineering Research Center of Water Engineering Safety and Resources Efficient \\ Utilization \\ ${ }^{2}$ School of Water Resources and Ecological Engineering, Nanchang Institute of Technology \\ No. 289 Tianxiang Avenue, Nanchang, Jiangxi Province, China \\ *Corresponding author \\ e-mail: nithuang@nit.edu.cn; phone: +86-13698095556 \\ (Received $28^{\text {th }}$ Oct 2016; accepted $28^{\text {th }}$ Feb 2017)
}

\begin{abstract}
The reasonable deployment of water resources can reduce resources consumption, increase the output of resources and thus ensure a sustainable economic development. The Pingshui River Basin in Jiangxi Province of China with developed economy but seriously lacking in water, was chosen as the study area and the dualistic distributed hydrological model of this region was established. Then, the water resources allocation objective, basic principles, river water operation rules and priority levels for all water consumers were fixed. Also, the objective function and constraint conditions were established, and forecast the water demand from various industries. Next, the optimal deployment of water resources in Pingshui River Basin was achieved through controlling variables including the water conservancy project operation rules, the channel discharge capacity, priority rules for water consumers and simulating the transport and transformation and interaction process under the natural and artificial dual coupling conditions. The deployment results show that there is seasonal and locality water shortage in Pingshui River Basin. Finally, based on the optimal water resources deployment results, utilization and exploitation status, specific countermeasures for water resources tapping and saving were proposed to increase the output of water resources and reduce its consumption.
\end{abstract}

Keywords: dualistic distributed hydrological model; optimal deployment; water demand; water supply; water resources balance

\section{Introduction}

With the development of economy and the increase in population, the rivalrousness of water utilizing of production and environment is aggravated, water resources have become one of the important factors constraining regional economic and social development (Wang et al., 2000). Water resources deployment is to allocate water resources to all users in the specific river basin or area on the principles of efficiency, justice and sustainable development (Wang et al., 2003). A reasonable water resources deployment is capable of ensuring the sustainable development of economy through reducing the water resources consumption per unit of output and environmental costs at a maximum level and promoting the output efficiency of national economy and the support capacity of social economy.

The research of water resources deployment started relatively early in foreign countries. In 1962, Mass became the first one to apply simulation technology to economic index of river basin exploitation (Mass, 1962), followed by a period with water quantity as the single index for allocation (Marks, 1971; Haimes and Hall, 1974). Afterwards, the coordinated development of social economy and ecological 
environment was attached to the study of water resources deployment, together with the indexes of water quantity and quality (Afzal and Noble, 1992; Watkins et al., 1995; Fleming et al., 1995; Lall, 1995; Allan, 1999). Ultimately, social justice and market regulation were paid attention to and market-oriented method was adopted, that is to solve the problem of water resources deployment with water rights and emission rights (Zhang et al., 1982; Ioslovich and Gutman, 2001; Erson and Rafael, 2002). The study of water resources deployment started later in China than in foreign countries. However, with the development of recent decades, the study in China has reached the internationally advanced level. The contents of deployment developed from the original surface water (Shi, 1982; Dong, 1983; Xu et al., 1997) to the joint operation of surface and underground water (Wang et al., 2004a, 2004b), followed by the unified dispatching of conventional water and unconventional water resources (Wang et al., 2001; Pei et al., 2006). The deployment objectives developed from the single maximization of economic benefit to regional multi-objective optimization (Ying et al., 2004; Wang et al., 2008; Zhao et al., 2009). The allocation approach developed from mathematical optimization (Chen et al., 2006; Huang et al., 2008) to the combination of simulating and optimizing hydrologic cycle (Chen et al., 2002; Xie et al., 2005; Gan et al., 2005) and the market-oriented method (Zhang, 2001; Wang and Xiao, 2001; Han et al., 2011; Wang et al., 2014). At the same time, due to the multi-objective, non-linear and large-scale system characteristics of water resource allocation model, many scholars applied some mathematical methods such as genetic algorithm, chaos optimization algorithm and grey theory to the solution of water resource deployment model to achieve the optimal results.

The water resources deployment model in the river basin has to take the following problems into consideration: (1) The deployment scheme cannot be confined to the maximization of economic benefit but take regional ecological environment into account as a whole; (2) Take into account the consuming priority orders in the areas of both upstream and downstream, and of both banks flanking the river; (3) Ensure that the water quantity and quality in the assessment sections can reach the standard through the combination of basin water function oriented zoning; (4) Management must compensate the upstream for the water protection; (5) In the influence of human activity, Hydrologic cycle presents a dualistic property of natural and artificial, the activity of water intake, water supply, water consumption and drainage has a remarkable influence on the hydrologic cycle in the river basin. However, in the current river basin water resources deployment model, the above problems are not considered comprehensively. With the factors above integrated and Pingshui River Basin as the field of study, a dualistic distributed hydrological model was established at first to quantitatively study the transformational relation of all elements within the river basin hydrologic cycle. And then the water resources allocation objective, basic principles, river water run scheduling rules and priority levels for all water consumers were fixed. Also, the objective function and constraint conditions were established, and forecast the water demand of various industries. Finally, The optimal deployment of water resources in Pingshui River Basin was achieved through controlling variables including the water conservancy project operation rules, the channel discharge capacity and priority rules for water consumers, and simulating the transport, transformation and interaction process of water resources under the natural and artificial dual coupling conditions. 


\section{Study Area}

The study area was the Pingshui River Basin, which is located at $114^{\circ} \mathrm{E} 01^{\prime}-113^{\circ} \mathrm{E} 37^{\prime}$ and $27^{\circ} \mathrm{N} 45^{\prime}-27^{\circ} \mathrm{N} 22^{\prime}$. It involves a large area in Pingxiang including Anyuan District, Development Zone, Xiangdong District, Shangli county, Luxi county and Lianhua county with a gross area of $1483 \mathrm{~km} 2$. Pingshui is an abranch of Xiangjiang River within the Dongting Lake water system. The source is Stone Hill of Shuijiang Town in Yichun city. It flows through Yuanzhou District in Yichun, Shangli county, Anyuan county, Xiangdong county, Luxi county, Lianhua county in Pingxiang City and runs into Hunan Province by the way of Xiangdong District.

Pingshui River Basin, which has subtropical monsoon climate, lies in the central of China. The mean annual precipitation in the area is $1594 \mathrm{~mm}$ while its mean annual temperature is $17.2^{\circ} \mathrm{C}$ with a mean annual evaporation of $1319 \mathrm{~mm}$.

\section{Deployment Process}

The process of Pingshui River Basin resources deployment consists of five parts, information gathering, water resources situation analysis, rational allocation, simulation analysis of hydrologic cycle and deployment result evaluation. Simulation process is made up mainly by the dualistic distributed hydrological model, rational deployment model of river basin water resources and evaluation model of basin water resources as shown in Fig 1.



Figure 1. The water resources deployment and operation simulation model

\section{Dualistic Distributed Hydrologic Model}

Distributed Hydrologic model adopts IWHRWEP model, which is based on WEP (Water and Energy transfer Process) model. The WEP model has been verified and applied in several fields in Japan. Owing to the study area is the inland river, we have made some improvements to the WEP model and verified thereafter. The computation unit of IWHRWEP model is square or oblong grid. The vertical direction structure of all gridding cells is shown in the Fig.2. From the top down are vegetation or building interception layer, depression retention layer on the earth surface, surface soil, the transitional zone layer, shallow groundwater and deep groundwater, etc. The two 
dimensional structure of the model is shown in Fig.3. Firstly, set the confluence direction by DEM and digital river to trace and calculate slope runoff. Next, trace and calculate slope runoff along the confluence direction from the upstream side to the downstream side by one-dimension kinetic wave model.

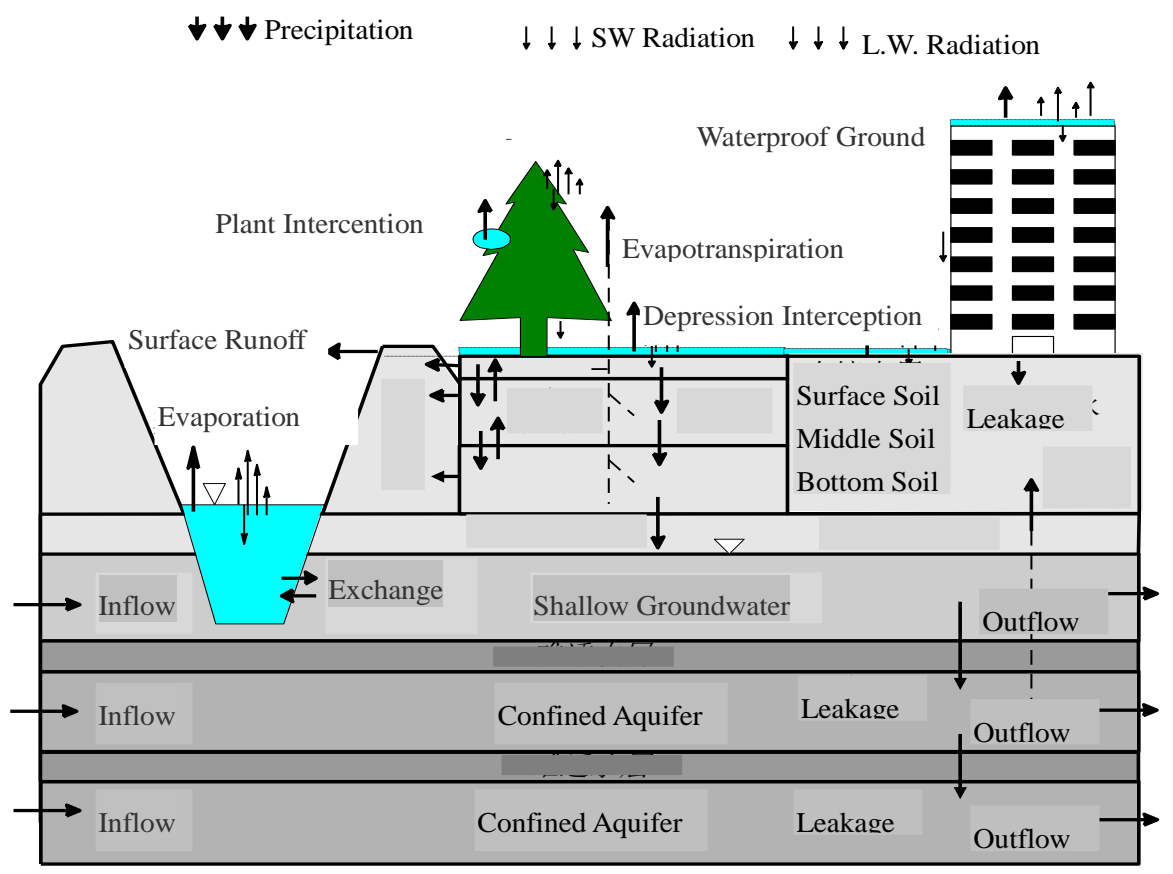

Figure 2. The vertical structure of IWHRWEP model in gridding cell

One-dimensional Overland Flow One-dimensional Overland Flow

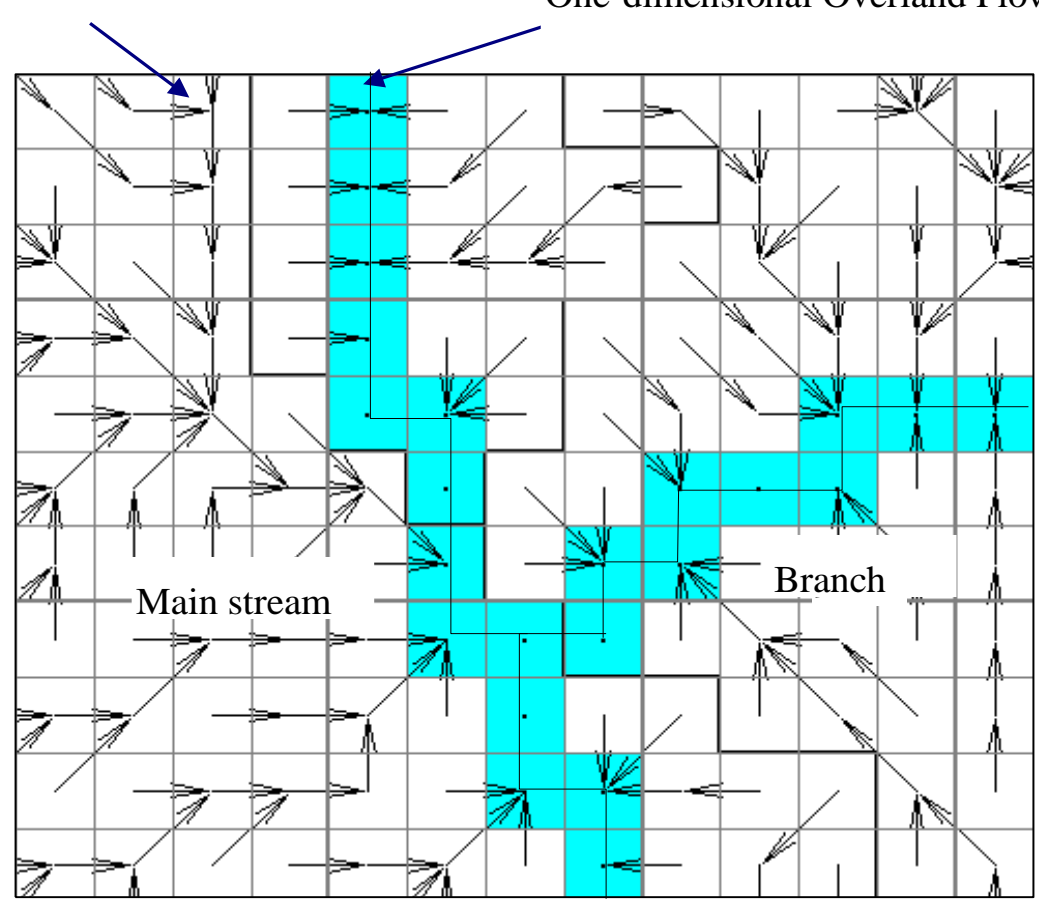

Figure 3. The two dimensional structure of IWHRWEP model 
The IWHRWEP model is based on the simulation of the cycling process of all hydrological factors and energy cycle in the hydrologic cycle system. The specific steps include:

(1)Collecting all sorts of basic data in hydrometeorological, physical geography and social economy, etc; (2) Using GIS technology to establish basic database and inputting data in accordance with the requirements of model file format; (3) Computing flow network according to digital elevation model (DEM) and basin runoffs generated in the digital channel and making watershed discretization in convenience to model verification and computation; (4) Estimating model parameters; (5) Choosing a correction phase to rectify the model (adjust model parameters). (6) Choosing a verification phase to certify the model. (7) Applying the model to the study area.

The Pingshui River Basin covers an area of $1483 \mathrm{~km}^{3}$, the distributed hydrological model to simulate the hydrological cycle, and divided the basin to 1538 units with square grids of $1 \mathrm{~km} \times 1 \mathrm{~km}$. Then, the study area was divided into six sub-watershed, as is shown in Fig. 4. A 20-year (from 1991 to 2010) simulation computation was conducted at a daily time step, and the five years from 2006 to 2010 is the model adjustment phase, which is accordance with the daily and monthly runoffs observed by the hydrometric station in Luxi county within the basin. The water volume computation results of all areas in Pingshui River Basin in 2015 are shown in Table 1.

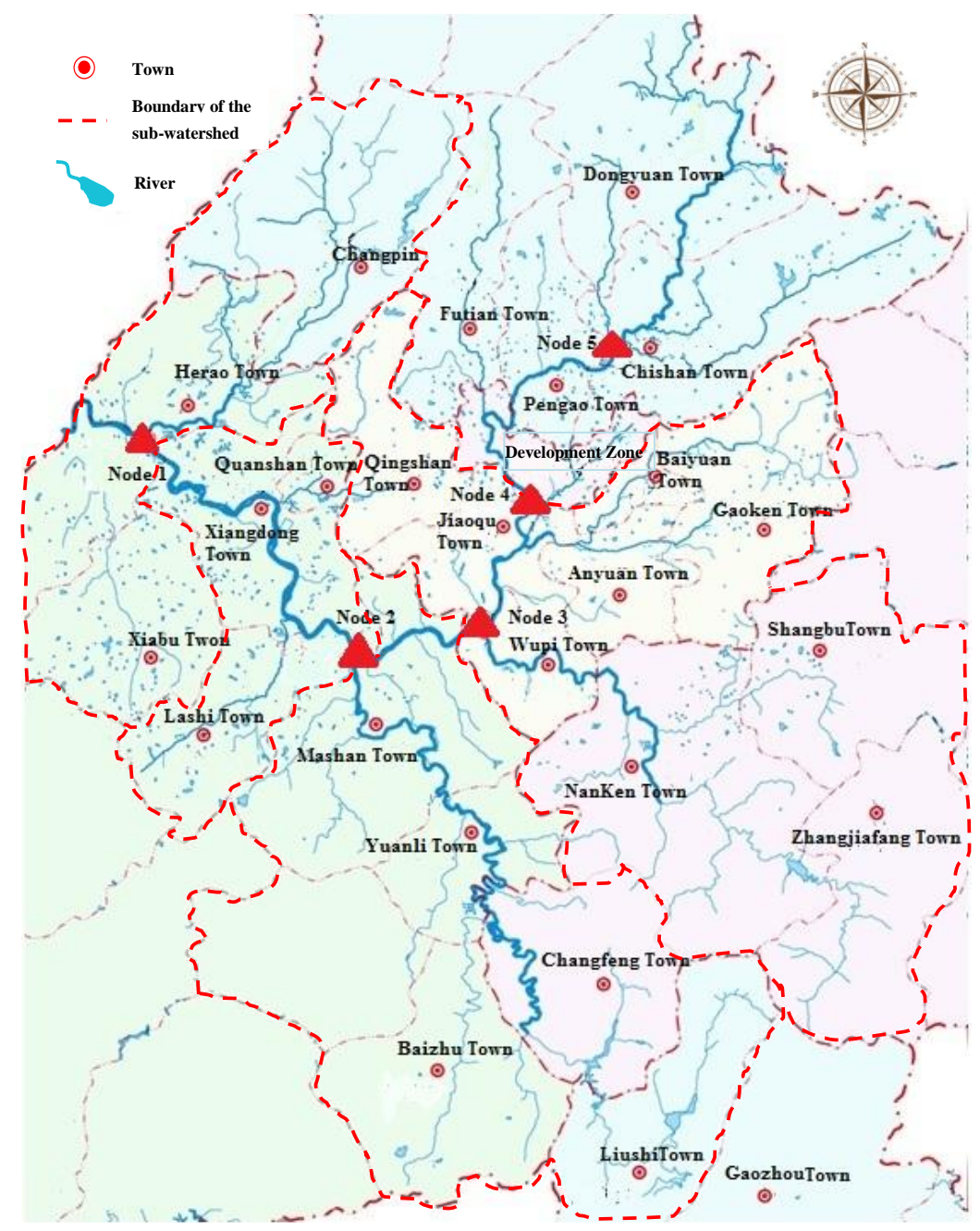

Figure 4. The river system of Pingshui watershed and the computer sub-watershed 
Table 1. Water budget of Pingshui River Basin in 2015 (Unit: ten thousand $m^{3}$ )

\begin{tabular}{|c|c|c|c|c|c|c|c|c|}
\hline \multirow{2}{*}{$\begin{array}{l}\text { County } \\
\text { (District) }\end{array}$} & \multicolumn{4}{|c|}{ Surface water } & \multicolumn{3}{|c|}{ Groundwater } & \multirow{2}{*}{$\begin{array}{c}\text { Total water } \\
\text { supply }\end{array}$} \\
\hline & $\begin{array}{l}\text { Water } \\
\text { storage }\end{array}$ & $\begin{array}{c}\text { Water } \\
\text { diversion }\end{array}$ & $\begin{array}{l}\text { Water } \\
\text { lifting }\end{array}$ & Total & $\begin{array}{c}\text { Shallow } \\
\text { groundwater }\end{array}$ & $\begin{array}{c}\text { Deep } \\
\text { groundwater }\end{array}$ & Total & \\
\hline Shangli & 2685 & 1459 & 1490 & 5634 & 1446 & 328 & 1774 & 7408 \\
\hline Luxi & 8424 & 854 & 1032 & 10310 & 1000 & 0 & 1000 & 11310 \\
\hline Xiangdong & 13131 & 11662 & 2363 & 27156 & 1200 & 0 & 1200 & 28356 \\
\hline Anyuan & 1845 & 1400 & 1100 & 4345 & 1500 & 663.5 & 2163.5 & 6508.5 \\
\hline $\begin{array}{c}\text { Developme } \\
\text { nt Zone }\end{array}$ & 211 & 285 & 210 & 706 & 150 & 82 & 232 & 938 \\
\hline Lianhua & 1160 & 329 & 315 & 1804 & 150 & 80 & 230 & 2034 \\
\hline Total & 27456 & 15989 & 6510 & 49955 & 5446 & 1153.5 & 6599.5 & 56554.5 \\
\hline
\end{tabular}

\section{Water Resources Deployment Model}

Water resources deployment objective can be divided into two aspects, including the macro level and micro level. At the macro level, the objective is to maintain favorable ecological environment and the sustainable development of social economy and coordinate the relationship between development and protection. At the micro level, the objective is to achieve the water deployment among all water consumers in the river basin to maximize the social economy benefit and ecological environment benefit.

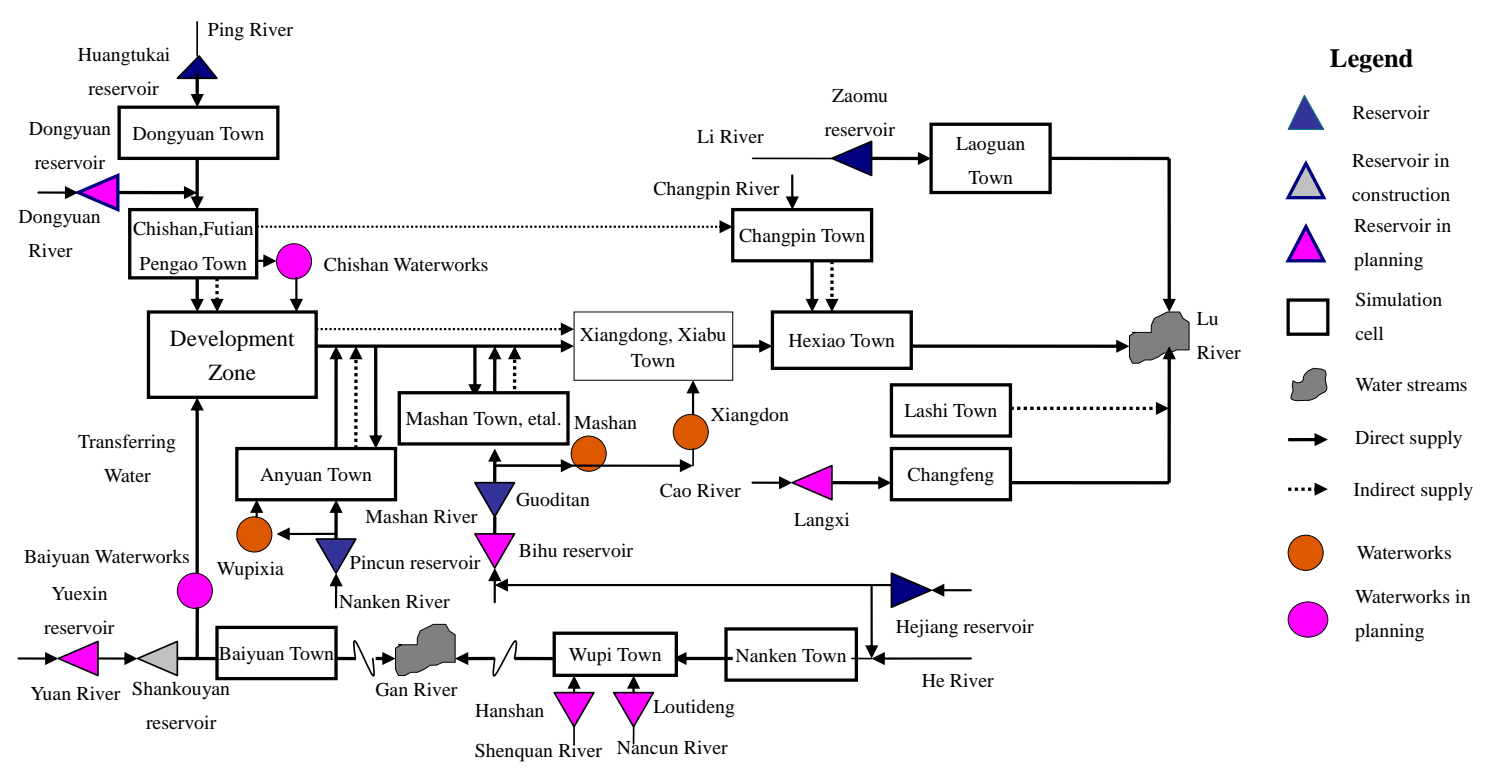

Figure 5. The water resources system network planning of Pingshui watershed

The generalized water resources system of Pingshui River Basin is the base of constructing the deployment model of basin water resources. The core of water deployment is the balance and unify of multi-source. In order to build a rational water resources deployment model, the first step is to generalize the actual basin water resources system into a network constituted by nodes and directed line segments. Nodes 
include important reservoirs, calculation units and river channel intersections, etc. Calculation units are basic and vital nodes. Supply of all water resources are conducted on the basis of calculation units. Directed line segments are representatives of natural rivers or channels, which embody the current transfer relationship among all nodes, as is shown in Fig.5.

Generalized model, generally made up of objective functions and constraint conditions, plays a significant role in the analysis of water resources system. Usually, the establishment of a mathematical model includes:

\section{(1) Objective function}

Water shortage is the major problem in Pingshui River Basin. Therefore, the objective function in the optimal deployment function are least aggregate of water scarcity in the Pingshui River Basin and mean water scarcity in any calculation units.

Suppose the least aggregate of water scarcity:

$$
\operatorname{MinZ}=\sum_{m=1}^{12} \sum_{u=1}^{U} \sum_{k=1}^{K} S t(m, u, k)
$$

In this equation, $S t(m, u, k)$ represents the water scarcity volume of calculation unit $u$ and water utilization type $k$ in the time period $m$.

Suppose mean water scarcity rate in all computing elements:

$$
\begin{gathered}
|\operatorname{Max} \eta-\operatorname{Min} \eta| \leq \varepsilon \\
\operatorname{Max} \eta=\operatorname{Max}\left(\eta w d_{y, m, u} \quad u=1,2, \ldots, U\right) \\
\operatorname{Min} \eta=\operatorname{Min}\left(\eta w d_{y, m, u} \quad u=1,2, \ldots, \quad U\right) \\
\eta w d_{y, m, u}=\frac{\sum_{j=1}^{4} S t_{(y, m, u, k)}}{\sum_{j=1}^{4} D_{(y, m, u, k)}}
\end{gathered}
$$

In this equation, $\eta w d_{y, m, u}$ represents the water scarcity rate of calculation unit $u$ and in the year $y$ and the time period $m$.

$S t_{(y, m, u, k)}$ represents the water scarcity volume of calculation unit $u$ and water user type $k$ in the year $y$ and the time period $m$.

$D_{(y, m, u, k)}$ represents the water demand volume of calculation unit $u$ and water user type $k$ in the year $y$ and the time period $m$.

\section{(2) Constraint conditions}

To compute water quantity constraint per unit:

$$
\begin{aligned}
S t(y, m, u, k)= & D(y, m, u, k)-Q(y, m, u, k)-H(y, m, u, k) \\
& -R(y, m, u, k)-\mathrm{G}(y, m, u, k)
\end{aligned}
$$


In this equation:

$S t(y, m, u, k)$ represents the water scarcity volume of calculation unit $u$ in the time period $m$;

$D(y, m, u, k)$ represents the water demand volume of calculation unit $u$ in the time period $m$;

$Q(y, m, u, k)$ represents the available spring volume of calculation unit $\mathrm{u}$ in the time period $m$;

$H(y, m, u, k)$ represents the river water supply of calculation unit $\mathrm{u}$ in the time period $m$;

$R(y, m, u, k)$ represents the reservoir water supply of calculation unit $\mathrm{u}$ in the time period $m$;

River node water quantity equilibrium constraints:

$$
\begin{aligned}
H(y, m, n) & =H(y, m, n-1)+H_{i}(y, m, n-1)+V_{r}(y, m, n-1) \\
& +Q(y, m, n-1)-V_{s}(y, m, n-1)-H_{0}(y, m, n-1) \\
& -L(y, m, n)
\end{aligned}
$$

In this equation:

$H(y, m, n)$ represents the inflow of river node $\mathrm{n}$ in the time period $m$;

$H(y, m, n-1)$ represents the inflow of river node $\mathrm{n}-1$ in the time period $m$;

$H_{i}(y, m, n-1)$ represents the water fall into the river node $\mathrm{n}-1$ in the time period $m$;

$V_{i}(y, m, n-1)$ represents the discharged water from reservoirs of river node $\mathrm{n}-1$ in the time period $m$;

$Q(y, m, n-1)$ represents the spring supply volume of river node $\mathrm{n}-1$ in the time period $m$;

$V_{s}(y, m, n-1)$ represents the water storage of channel node $\mathrm{n}-1$ in the time period $m$;

$H_{o}(y, m, n-1)$ represents the water drawn away of river node $\mathrm{n}-1$ in the time period $m$;

$L(y, m, n)$ represents the lost water volume of river node $\mathrm{n}-1$ in the time period $m$.

Reservoir water equilibrium constraints:

$$
\begin{aligned}
\mathrm{V}(\mathrm{y}, \mathrm{m}+1, \mathrm{i}) & =\mathrm{V}(\mathrm{y}, \mathrm{m}, \mathrm{i})+V s(\mathrm{y}, \mathrm{m}, \mathrm{i}) \\
& -V r(y, m, i)-\mathrm{L}(y, m, i)
\end{aligned}
$$

In this equation:

$\mathrm{V}(\mathrm{y}, \mathrm{m}, \mathrm{i})$, represents respectively the original storage capacity of reservoir $i$ in the time period $m$;

$\mathrm{V}(\mathrm{y}, \mathrm{m}+1, \mathrm{i})$ represents respectively the final storage capacity of reservoir $i$ in the time period $m$;

$V s(\mathrm{y}, \mathrm{m}, \mathrm{i})$ represents the water storage of reservoir $i$ in the time period $m$;

$\operatorname{Vr}(y, m, i)$ represents the discharged water of reservoir $i$ in the time period $m$;

$\mathrm{L}(y, m, i)$ represents the lost water volume of reservoir $i$ in the time period $m$.

Water storage capacity constraints:

$$
V_{\min }(i) \leq V(y, m, i) \leq V_{\max }(i)
$$




$$
V_{\min }(i) \leq V(y, m, i) \leq V^{\prime}{ }_{\max }(i)
$$

In the two equations:

$V_{\text {min }}(i)$ represents the dead storage of reservoir $\mathrm{i}$;

$V(y, m, i$,$) represents the dead storage capacity of reservoir \mathrm{i}$ in the time period $\mathrm{m}$;

$V^{\prime}{ }_{\max }(i)$ represents the capacity of reservoir $i$ in the limiting stage during flood;

$V{ }_{\max }(i)$ represents the active storage of reservoir $i$.

Diversion and delivery water quantity constraint:

$$
P(y, m, u) \leq P_{\max }(u)
$$

In this equation:

$\mathrm{G}(\mathrm{y}, \mathrm{m}, \mathrm{u})$ represents the groundwater exploitation volume of calculation unit $u$ in the time period $m$.

$\mathrm{P}^{\prime} \max (\mathrm{u})$ represents the groundwater exploitation capacity per month of calculation unit $u$;

Gmax(u) represents the greatest groundwater exploitation volume permitted within a year of calculation unit $u$.

The constraint of least guarantee rate of water supply:

$$
\begin{gathered}
\beta(y, m, u, k) \geq \beta \min (m, u, k) \\
\beta(y, m, u, k)=\frac{S p(y, m, u, k)}{D(y, m, u, k)}
\end{gathered}
$$

In this equation:

$\beta(y, m, u, k)$ represents the guarantee rate of water supply of calculation unit $u$ and water user type $k$ in the year $y$ and the time period $m$;

$\beta \min (m, u, k)$ represents the lowest water supply guarantee rate required by the water user type $k$ and calculation unit $u$ in the time period $m$;

$S p_{(y, m, u, k)}$ represents the water supply volume of calculation unit $u u$ and water user type $k$ in the time period $m$;

$D_{(y, m, u, k)}$ represents the water demand of calculation unit $u u$ and water user type $k$ in the time period $m$.

\section{(3) Boundary conditions}

\section{Starting regulation reservoir capacity:}

$$
V(1, i)=\operatorname{Vo}(i)
$$

In this equation:

$V(1, i)$ represents the storage capacity of reservoir i in January;

$V o(i)$ represents the starting regulation capacity of reservoir i; 


\section{Delivery condition:}

$$
V(i, m+1)=V(i, m)
$$

In this equation:

$V(i, m+1)$ represents the initial storage capacity of reservoir $\mathrm{i}$ in the month $\mathrm{m}+1$;

$V(i, m)$ represents the final storage capacity of reservoir i in the month $m$.

\section{Results}

According to distributed hydro-logical model, water resources deployment model and operation rules, water resources deployment computations are conducted respectively in 2015 and 2020 in the frequency of $50 \%$ and $95 \%$.

The water resources deployment results in 2015 and 2020 show that the water shortage is relatively grave in the third and fourth node control area. The allocation computing results reached in the whole study area, 3-4 node control area and 4-5 node control area under the frequencies of $50 \%$ and $95 \%$ are drawn into figures with Excel to intuitively present the temporal and spatial variation in regional water supply and demand for favorable comparison analysis, as are shown from Fig. 6 to Fig. 8 .

The water shortage of the study area mainly takes the form of seasonal and localized ones. Mostly because of the lack of the water conservancy project, and some caused by the pollution.

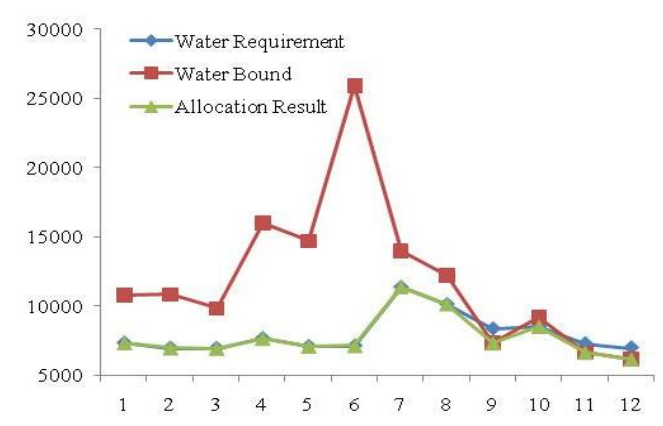

(a) $2015 / 50 \%$

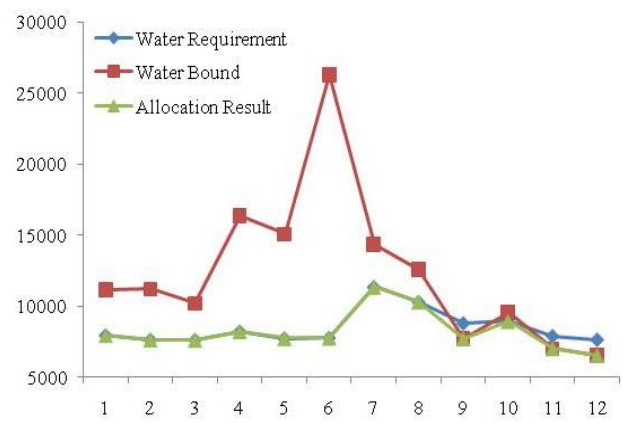

(c) $2020 / 50 \%$

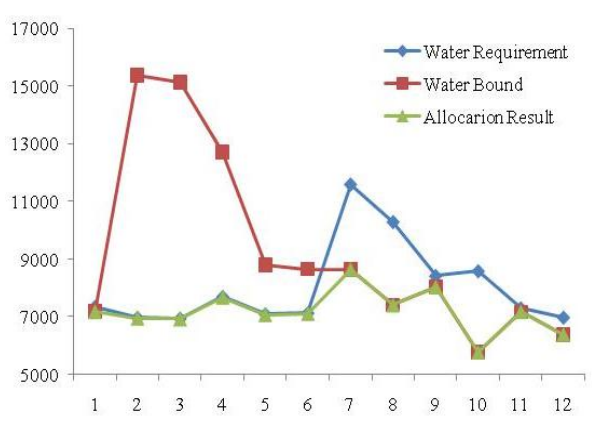

(b) $2015 / 95 \%$

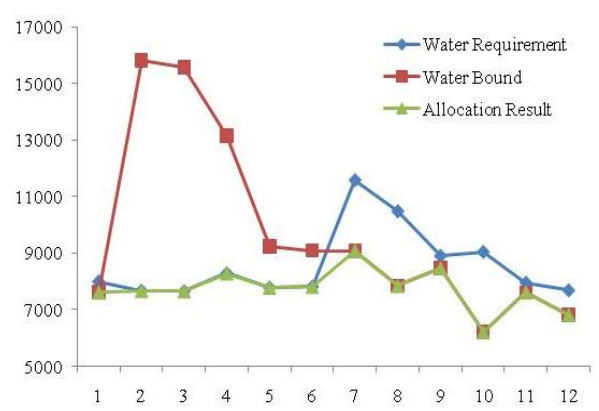

(d) $2020 / 95 \%$

Figure 6. The water resources allocation results in different year and frequency 


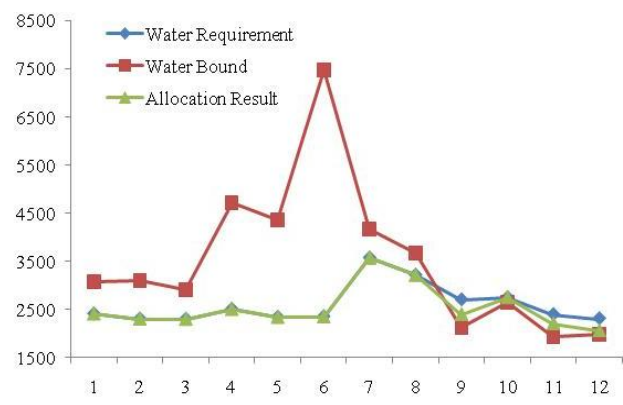

(a) $2015 / 50 \%$

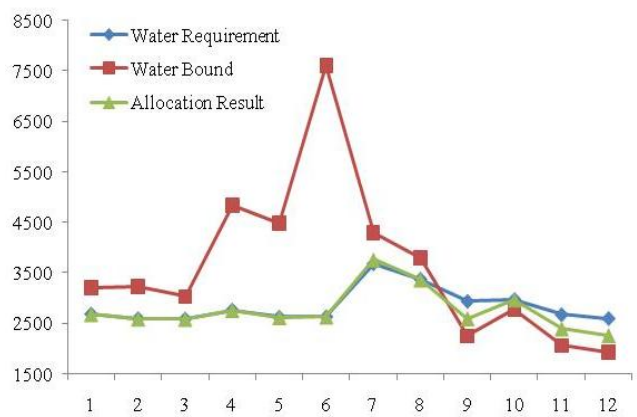

(c) $2020 / 50 \%$

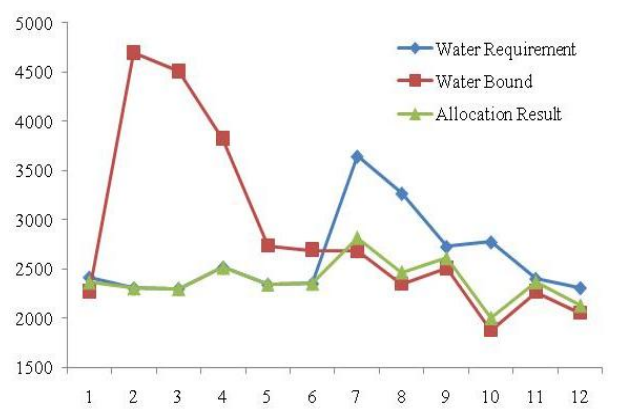

(b) $2015 / 95 \%$

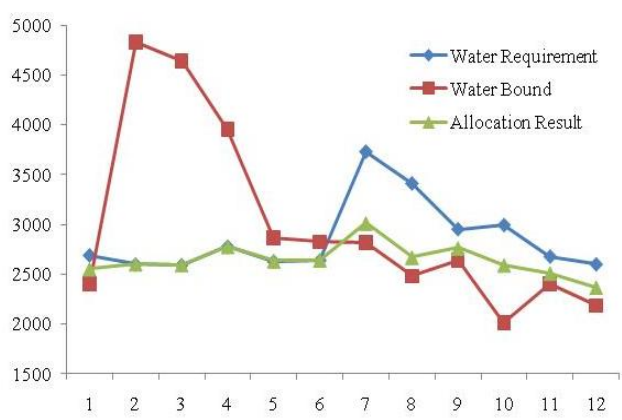

(d) $2020 / 95 \%$

Figure 7. The water resources allocation results between node 3 and node 4 in different year and frequency

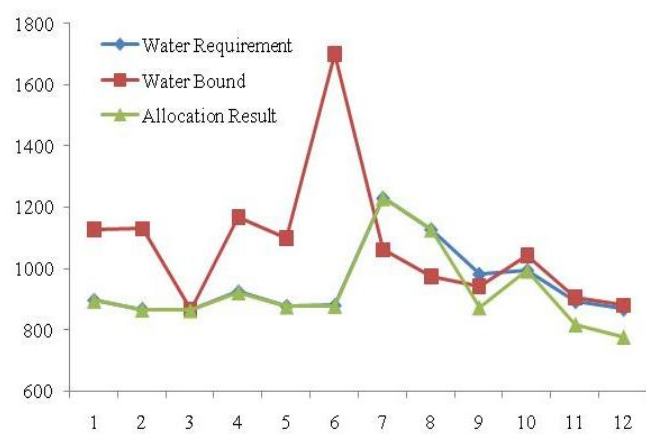

(a) $2015 / 50 \%$

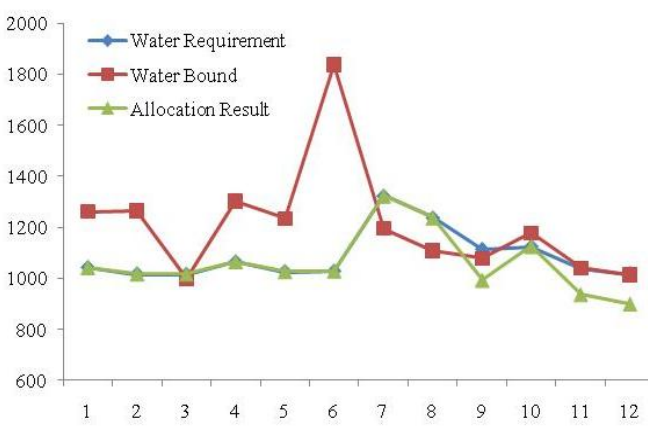

(c) $2020 / 50 \%$

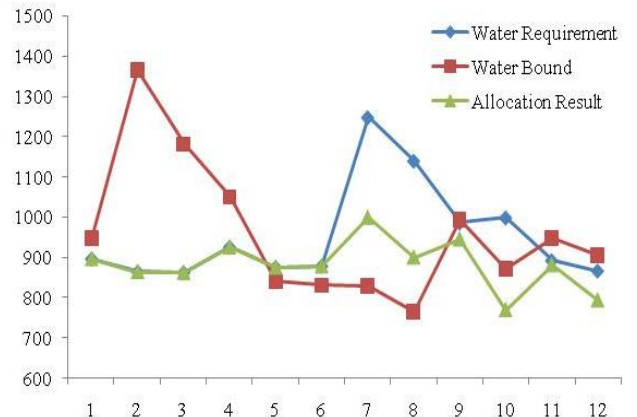

(b) $2015 / 95 \%$

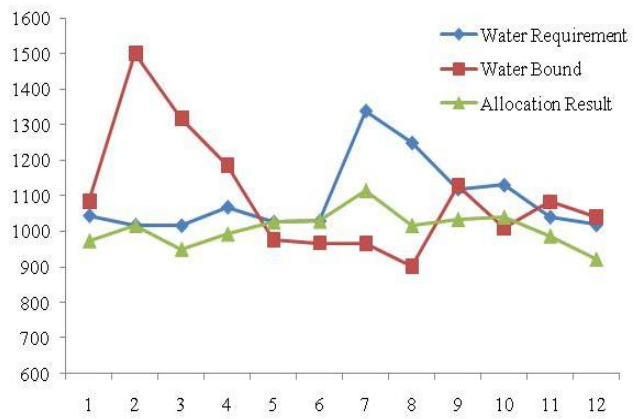

(d) $2020 / 95 \%$

Figure 8. The water resources allocation results between node 4 and node 5 in different year and frequency 
(1) In the study area, the users are not well-distributed. Water users are concentrated on the third and fourth node control area that is densely populated and advanced in industrial development. The water consumed for industrial takes up a rather large proportion. Also, partial water shortage is relatively severe in the controlled area and mainly occurs from July to October. In the case with a frequency of $50 \%$, the water shortage in September of 2015 is as high as 13.19 billion m3. In the case with a frequency of $95 \%$, the water shortage in July of 2015 is as high as 17 billion $\mathrm{m}^{3}$. In the case with a frequency of 50\%, the water shortage in September of 2020 is as high as 15.49 billion $\mathrm{m} 3$. In the case with a frequency of $95 \%$, the water shortage in July of 2020 is as high as 17.79 billion $\mathrm{m}^{3}$.

(2) The rainfall amount of most places in the study area are totally different. Water conservancy project are insufficient in the basin. The reservoirs are old and diminishing in their regulation and storage capacity. There is a great gap between practical water supply capacity and designed water supply capacity. As a result, a large amount of surplus water during wet season is abandoned while the water supplies in dry season are inadequate, hence the serious seasonal water shortage.

(3) In the study area, the water resources waste is quite severe. Agricultural irrigation water-using coefficient is low here and the repeated use rate of industrial water is far lower than that of advanced level. Therefore, the water saving need to be improved.

\section{Conclusion}

To achieve the effective utilization and optimal deployment of regional water resources and to ameliorate the water shortage in Pingxiang city, the policy of increasing the output of water resources and reducing water consumption must be contained in the guiding ideology. Tapping and saving, governance and protection should come first and water conservancy and exploitation from top to bottom come later. Exploitation of water resources should be carried out in the process of governance and protection and vice versa.

To fulfill the sustainable utilization of water resources within the Pingshui River Basin, it is must to increase the output of water resources and reduce water exploitation. Also it is advised for all sub-regions to adopt different measures according to their own characteristics.

(1) The planned water resources projects will tapping the water supply capacity of study area in future. The projects include Bihu Reservoir of Mashan River, Tianzhong Reservoir of new urban district in Pingxiang city and Dongyuan Reservoir of Dongyuan river as well as the water diversion project of Shankou Hill in Yuanshui basin. What is more important is to fully tap the potential of existing water supply projects via the engineering measures such as danger-removing of reservoirs, reinforcement of banks, water division and project reconstruction, etc.

(2) Water saving of agricultural should be placed on a prime position. On the one hand, water saving transformation in channel system should be upgraded. On the other hand, non-engineering measures of water saving should be adopted, like making use of rainfall, strengthening field management and water deployment, and adjusting planting structure, etc.

(3) Water saving in industry, due to the reality that industrial and mining enterprises are dominant in Pingxiang city, water saving should be conducted from the enterprises themselves and mine water can also be used in the production process, which will help 
ease up the contradiction of supply and demand in partial regions. The government should strengthen water management, strictly control the emission of pollution and propel the upgrade of technology and facilities through various administrative means. Also, the government should promote the sewage treatment rate and recycled water utilization rate with the decreasing of water supply pipe network leakage as a chief means.

(4) Domestic water demand should be restricted within the standard fit in with the economic development level and living conditions. The constraints which population and resources have on water demand and supply should be taken into account. Thus, the government should put more effort on the water-saving activities in urban areas, promote domestic water-saving devices and increase domestic water utilization rate through strengthening management with the aim to develop into a water-saving city.

Acknowledgements. This work was supported by the science and technology project of Jiangxi Provincial Educational Department (GJJ151122), the NSFC (51569015, 51269020), Jiangxi Provincial Department of Science and Technology (20161BBG70049), Supported by the Open Foundation of JiangXi Engineering Research Center of Water Engineering Safety and Resources Efficient Utilization, Grant NO. OF201609.

\section{REFERENCES}

[1] Afzal, J., Noble, D. H.(1992): Optimization model for alternative use of different quality irrigation waters. - Journal of Irrigation and Drainage Engineering 118: 218-228.

[2] Allan, T. (1999): Productive efficiency and allocative efficiency: why better water management may not solve the problem. - Agricultural Water Management 40(1): 71-75.

[3] Chen, N. X., Li, Y. P., Xu, C. G.(2006): Optimal deployment of water resources based on multi-objective genetic algorithm. - Journal of Hydraulic Engineering 37: 308-313.

[4] Chen, X. H., Chen, Y. Q., Lai, G. Y.(2002): Optimal allocation of water resources in Dongjiang River Basin. - Journal of Natural Resources 17: 366-372.

[5] Dong, Z. A.(1983): Application of the variation constraint method and the maximum economic benefit criterion in optimization of reservoir regulation of hydroelectric station. - Journal of hydroelectric engineering 2: 10-19.

[6] Erson, K., Rafael, K.(2002): Water allocation for production in a semiarid region. Water Resources Development 3: 391-407.

[7] Fleming, A., Adams, M., Kim, S.(1995): Regulating groundwater pollution: effects of geo-physical response assumptions on economic efficiency. - Water Resources Study 4: 1069-1076.

[8] Gan, Z. G., Jiang, Y. Z., Lu, F.(2005): Water resources deployment model for Beijing City. - Journal of Hydraulic Engineering 39: 91-102.

[9] Haimes, Y. Y., Hall, W. A.(1974): Multiobjectives in water resources systems analysis: the surrogate worth trade off method. - Water Resources Research 10: 615-624.

[10] Han, Y., Huang, Y. F., Wang, G. Q.(2011): Study on coordination evolvement of complex water resources system with interval uncertainty. - Journal of Hydraulic Engineering 8: 5-11.

[11] Huang, X. F., Shao, D. G., Gu, W. Q.(2008): Optimal water resources deployment based on multi-objective chaotic optimization algorithm. - Journal of Hydraulic Engineering 2: 183-188.

[12] Ioslovich, I., Gutman, P.(2001): A model for the global optimization of water prices and usage for the case of spatially distributed sources and consumers. - Mathematics and Computer in Simulation 4: 347-356.

[13] Lall, U. (1995): Yield model for screening surface and ground-water development. - 
Journal of Water Resources Planning and Management 1: 9-22.

[14] Li, W. Q., Xie, J. C., Li, J. X.(2012): Water resources allocation based on the grey theory and the improved electromagnetism-like algorithm. - Journal of Hydraulic Engineering 12: $1447-1456$.

[15] Marks, D. H.(1971): A new method for the real time operation of reservoir systems. Water Resources Research 23: 1376-1390.

[16] Mass, A.(1962): Design of water-resource systems. - Harvard University Press, New York.

[17] Pei, Y. S., Zhao, Y., Lu, C. Y.(2006): Rational Water Resources Allocation of Economic-ecosystem. - The Yellow River Water Conservancy Press, Zhengzhou.

[18] Shi, X. C., Wang, H.(1982): Application of reliability constrained marcovian decision programming in optimization of reservoir regulation of hydroelectric station. - Journal of hydroelectric engineering 7: 2-7.

[19] Wang, D. X., Wang, H., Ma, J.(2000): Water resources supporting capacity regional development in China. - Journal of Hydraulic Engineering 11: 21-26.

[20] Wang, H., Chang, B. Y., Qing, D. Y.(2004a): The research of Heihe river basin water resources allocation. - China Water Resources 11: 215-220.

[21] Wang, H., Qin, D. Y., Wang, J. H.(2003): The reasonable water resources deployment of Yellow river valley, Huaihe river valley and the Haihe river valley. - Science Press, Beijing.

[22] Wang, H., Wang, J. H., Qing, D. Y.(2004b): Research advances and direction on the theory and practice of reasonable water resources allocation. - Advances in Water Science 15: 128-132.

[23] Wang, H., You, J. J.(2008): Advancements and development course of research on water resources deployment. - Journal of Hydraulic Engineering 10: 138-145.

[24] Wang, J. S., Liu, C. M., Yu, J. J.(2001): Theoretical models for space and temporal distribution of water resources. - Journal of Hydraulic Engineering 32: 7-14.

[25] Wang, L., Xiao, Z. L., Liang, X. J.(2014): MIKE BASIN model in water resources allocation in Jilin city. - China Rural Water and Hydropower 5: 366-471.

[26] Wang, X. J., Xiao, W.(2001): Market mechanism of water resources allocation and its efficiency. - Journal of Hydraulic Engineering 12: 26-31.

[27] Watkins, D., Mckinney, R., Daene, R.(1995): Optimization for incorporation risk and uncertainty in sustainable water resources planning. - International Association of Hydrological Sciences 11: 1905-1914.

[28] Xie, X. M., Yue, C. F., Ruan, B. Q.(2005): Multipurpose decomposition control model based on primary water-purified water coupling allocation. - Advances in Science and Technology of Water Resources 3: 156-173.

[29] Xu, X. Y., Wang, H., Gan, H.(1997): The macro-economy water resources planning theory and method in north China. - The Yellow River Water Conservancy Press, Zhengzhou.

[30] Ying, M. W., Xie, X. M., Wang, H.(2004): Water resources allocation model based on domestic, productive, and ecologic-environmental water consumption. - Advances in Science and Technology of Water Resources 2: 2-10.

[31] Zhang, F.(2001): To optimize water distribution in viewpoint of property right. - China Water Resources 11: 23-28.

[32] Zhang, P., Zhao, Y., Zhen, C. Y.(2006): Optimal allocation of water resources in the water import areas of the east route of the South-to-North water transfer region. Resources Science 18: 453-471.

[33] Zhang, Y. C., Li, F. S., Xiong, S. Y.(1982): The variable direction search method and its application in hydropower station reservoir optimal dispatching. - Journal of hydroelectric engineering $2: 1-9$.

[34] Zhao, Y., Pei, Y. S., Wang, J. H.(2009): The progress of water resources rational allocation. - Advances in Science and Technology of Water Resources 3: 29-40. 